This item was submitted to Loughborough's Research Repository by the author.

Items in Figshare are protected by copyright, with all rights reserved, unless otherwise indicated.

\title{
Climate change and river flooding: part 2 sensitivity characterisation for british catchments and example vulnerability assessments
}

PLEASE CITE THE PUBLISHED VERSION

http://dx.doi.org/10.1007/s10584-013-0726-3

\section{PUBLISHER}

(c) Springer Science+Business Media Dordrecht

\section{VERSION}

AM (Accepted Manuscript)

\section{PUBLISHER STATEMENT}

This work is made available according to the conditions of the Creative Commons Attribution-NonCommercialNoDerivatives 4.0 International (CC BY-NC-ND 4.0) licence. Full details of this licence are available at: https://creativecommons.org/licenses/by-nc-nd/4.0/

\section{LICENCE}

CC BY-NC-ND 4.0

\section{REPOSITORY RECORD}

Prudhomme, Christel, Alison L. Kay, Sue M. Crooks, and Nick S. Reynard. 2019. "Climate Change and River Flooding: Part 2 Sensitivity Characterisation for British Catchments and Example Vulnerability Assessments". figshare. https://hdl.handle.net/2134/21118. 


\section{Climatic Change \\ CLIMATE CHANGE AND RIVER FLOODING: PART 2 SENSITIVITY CHARACTERISATION FOR BRITISH CATCHMENTS AND EXAMPLE VULNERABILITY ASSESSMENTS \\ --Manuscript Draft--}

\begin{tabular}{|c|c|}
\hline Manuscript Number: & CLIM-D-12-00434R1 \\
\hline Article Type: & Research Article \\
\hline Corresponding Author: & $\begin{array}{l}\text { Christel Prudhomme } \\
\text { Centre for Ecology and Hydrology } \\
\text { UNITED KINGDOM }\end{array}$ \\
\hline \multicolumn{2}{|l|}{$\begin{array}{l}\text { Corresponding Author Secondary } \\
\text { Information: }\end{array}$} \\
\hline Corresponding Author's Institution: & Centre for Ecology and Hydrology \\
\hline \multicolumn{2}{|l|}{ First Author Secondary Information: } \\
\hline \multirow[t]{4}{*}{ Order of Authors: } & Christel Prudhomme \\
\hline & Alison L Kay \\
\hline & Sue Crooks \\
\hline & Nick Reynard \\
\hline \multicolumn{2}{|c|}{ Order of Authors Secondary Information: } \\
\hline Abstract: & $\begin{array}{l}\text { This paper is the second of a series describing a scenario-neutral methodology to } \\
\text { assess the sensitivity and vulnerability of British catchments to changes in flooding due } \\
\text { to climate change. In paper one, nine flood sensitivity types were identified from } \\
\text { response surfaces generated for } 154 \text { catchments. The response surfaces describe } \\
\text { changes in } 20 \text {-year return period flood peaks (RP20) in response to a large set of } \\
\text { changes in precipitation, temperature and potential evapotranspiration. In this paper, a } \\
\text { recursive partitioning algorithm is used to link families of sensitivity types to catchment } \\
\text { properties, via a decision tree. The tree shows } 85 \% \text { success characterising the four } \\
\text { sensitivity families, using five properties and nine paths. Catchment annual average } \\
\text { rainfall is the primary partitioning factor, with drier catchments having a more variable } \\
\text { response to climate (precipitation) change than wetter catchments and higher } \\
\text { catchment losses and permeability being aggravating factors. The full sensitivity- } \\
\text { exposure-vulnerability methodology is illustrated for two catchments: sensitivity is } \\
\text { estimated by using the decision tree to identify the sensitivity family (and its associated } \\
\text { average response surface); exposure is defined from a set of climate model projections } \\
\text { and combined with the response surface to estimate the resulting impacts (changes in } \\
\text { RP20); vulnerability under a range of adaptive capacity thresholds is estimated from } \\
\text { the set of impacts. Even though they are geographically close, the two catchments } \\
\text { show differing vulnerability to climate change, due to their differing properties. This } \\
\text { demonstrates that generalised response surfaces characterised by catchment } \\
\text { properties are useful screening tools to quantify the vulnerability of catchments to } \\
\text { climate change without the need to undertake a full climate change impact study. }\end{array}$ \\
\hline Response to Reviewers: & See attached response to comments \\
\hline
\end{tabular}




\section{Response to reviewers comments on "CLIMATE CHANGE AND RIVER FLOODING: PART 2 SENSITIVITY CHARACTERISATION FOR BRITISH CATCHMENTS AND EXAMPLE VULNERABILITY ASSESSMENTS"}

We would like to thank the editor and 3 reviewers for helpful comments. Our response to these comments is provided below.

\section{Editor:}

It should be noted that some of the comments (especially from Reviewer \#1) focus on the breakdown of information between this manuscript and the companion piece. In revising this manuscript, please take into account the reviews on Part 1 , and the comments, made by reviewers to both manuscripts, about the rationale for your approach (20 yr flood peak, not examining higher frequency flows). The response to the reviews of Part 1 articulated the rationale quite well; if incorporated into the next revised Part 1 manuscript, you can refer to that rationale in Part 2. Otherwise, please pay careful attention to all the reviewers' concern; the reviewers, while generally positive about the manuscript, raise some key points about layout and wording (confusing acronyms!) that we expect to see addressed.

A paragraph has been added at the end of Part 1 explaining why the sensitivity framework has been set-up and implemented as it has (e.g. not including changes in higher-frequency variability) - we now refer to that from the Discussion this paper. The acronyms FRS, FST and FSF have been replaced, as requested.

\section{Reviewers' comments:}

\section{Reviewer \#1:}

While I very much like the approach in general, despite its obvious simplifications, I am not convinced this second part is motivated. Honestly, this second part looks to me somewhat as a collection of left-overs. I am sorry, but I was not able to understand the added value of the tree-study and found this part rather difficult to follow. The more in-depth discussion of two different catchments has potential interest, but could probably easily be added to part 1 . It is obviously a bit unfortunate that this comparison is limited to only two catchments. If a part 2 should be motivated, this would have to be extended/generalized.

The aim of this second part is generalisation of the response-surface methodology to ungauged/unmodelled catchments, by enabling estimation of the sensitivity type, and so response surface, of such catchments from their catchment properties. We have tried to clarify this in the introduction.

One issue that needs more discussion is the question in how far this simplified approach is suitable for flood vulnerability assessments. One could argue that the use of monthly change factors is too much of a simplification to allow a realistic assessment of potential changes in hydrological extremes. This is now discussed at the end of Part 1 of this pair of papers (and referred to from the Discussion of this paper), as requested by the editor.

p13, 26: by now already CMIP5 data is available, needs to be updated $\mathrm{OK}$, this sentence has been changed.

It might be good to mention that this simple approach would not work for catchments with snow influence. 
A snowmelt module was used as a pre-processor on precipitation input in the hydrological models to improve model simulation and allow for possible changes in snow/rain impact on the runoff regime in upland catchments. However, the number of catchments where snow sufficiently impacts on flood peaks to affect flood frequency is limited in Britain, hence related catchment properties do not appear in the decision trees. However, it is mentioned in Table $d$ of the supplementary material as a possible (contributory) cause of the DampedExtreme and Damped-High sensitivity types. Text has been added to the Discussion (Section 4) to include snowmelt.

A reference the authors might want to consider is Köplin, N., Schädler, B., Viviroli, D., and Weingartner, R.: Relating climate change signals and physiographic catchment properties to clustered hydrological response types, Hydrol. Earth Syst. Sci., 16, 2267-2283, doi:10.5194/hess-16-2267-2012, 2012. This reference is included/discussed in Part 1, and has been included in the snowmelt discussion added to this paper.

\section{Reviewer \#2:}

I very much like the approach that the authors have chosen which uses a large amount of information in a way that can be of practical relevance for water authorities. The division into two parts makes sense, given the amount of material that the authors present. However, this division is not always kept clear and the readability of the paper could be improved by making it more explicit. Generally, I see four issues with paper II that could be improved:

1. The introduction should more clearly describe the purpose and objectives of this paper and its relation to paper I. For example, the introduction does not even say that there is a part I to the current paper, it only cites part $I$ in one sentence (and the citation is to another paper at the same time, P3/L39). The main motivation for paper II---a screening tool that could potentially be applied to all catchments in the UK---is given only in the introduction of paper I but missing in paper II. The introduction should present the main ideas of paper I, but also explicitly refer to it. The introduction has been edited to clarify things.

2. Some sections are difficult to understand without reading paper I first. Some of the details could be left out, as these are the topic of the first paper, but this paper should more directly point to the relevant part of paper I. In the detailed comments below I try to give a few suggestions how this could be done. Add a short description of how the climate scenarios were constructed (details in paper I, shorter in paper II with reference to the details in paper I).

We tried to make the information in this paper stand on its own as far as possible, but in such a linked pair of papers we feel it is inevitable that part 2 will be clearer after reading part 1. We have now tried to improve the referencing of relevant parts of part 1 though, as requested. We have also now provided a better introduction to the harmonic function parameters (Section 3.1 Stage 2), with reference to the relevant part of Part 1.

3. The discussion about how seasonal $T$ and $P$ changes have been incorporated would better fit in paper I and I suggest to remove it from this paper. Instead, a discussion about the adaptive capacity threshold could be added, covering the background of the $20 \%$ number, the usefulness of a single number for all catchments and alternatives. Also, I think the paper would 
benefit from some discussion on how uncertainties deriving from the hydrological models could be incorporated into the screening tool (refer to studies estimating hydrological impact model uncertainty; an example of impact model uncertainty quantified for response surfaces is given by Fronzek et al. 2011, doi:10.5194/nhess-11-2981-2011). The standard deviation number given in Table 3 represents the uncertainty due to using different flood response surfaces from the same FST and for different T-change levels. But this is not the only source of uncertainty.

The discussion relating to the set up of our sensitivity framework approach has now been moved to Part 1 . Further comment on the national $20 \%$ allowance leaving some catchments more vulnerable than others has been added (end of Section 3.2), as has comment on development of regional allowances (end of Section 5). The discussion on additional uncertainty from this methodology (end of Section 3.1) has been enhanced (with references), and will be the subject of a future paper.

4. The three acronyms FST, FSF and FRS are difficult to remember and can be easily confused; I wonder if the term FSF cannot be dropped. I find it a bit confusing that paper I establishes 9 classes from the 154 flood response surfaces, but paper II boils them further down to 4 groups. Could not paper I come up with these four groups directly? This would also simplify the naming convention used for these different types of groups, as "flood sensitivity family (FSF)" can be dropped and only "flood sensitivity type (FST)" retained. In many places in the text, FSF and FST seem to have been used as synonyms anyway (e.g. P8/L50, P9/L1, P14/L31). Elsewhere (P14/L1) the terms "classification" and "characterisation" are used to distinguish these. We have removed the FRS, FST and FSF shorthand, using the terms 'response surface', 'sensitivity type' and 'sensitivity family' instead. We have retained 9 sensitivity types in part 1 , as these are valid across a range of return periods; the consolidation of 9 types into 4 families is only required for the characterisation for higher return periods. This is explained in Sections 2.1 and 2.3, and we have tried to make this distinction clearer.

I think these issues can be handled quite easily and I try to give a few concrete suggestions in the specific comments below. I recommend the manuscript to be accepted for publication after consideration of the above minor revisions and the specific comments below on individual sections of the manuscript.

Specific comments

5. Page 3, Line 43: The term "scenario sensitivity analysis" might be misleading, instead I suggest the following: "? is used to undertake a detailed sensitivity analysis comprising 4200 combinations of changes in P, T and PE for 154 catchments ?"

The sentence has been changed as suggested.

6. P4, L30: Add how many catchments there are in Britain that could potentially be assessed with the screening tool.

Information has been added.

7. P5, L54: Add the number of properties and describe these shortly or give examples.

Information has been added.

8. P6, L21ff: It is not clear to me how a final decision tree is defined by expert judgement. Is the $R$ package not calculating a single decision tree? 
A number of similarly performing trees were derived, according to whether certain properties were allowed or not, and decisions had to be made regarding tree pruning; expert judgment was used for these.

9. P7, L23: Using "observed FSF" is misleading. I suggest to use "? compares the simulated FSF to that given by the decision tree". Refer to the Suppl. Material which shows the contingency table.

The terms 'simulated' and 'assigned' have been used in place of 'observed' and 'attributed'; relatively short terms were necessary due to use in a number of places in the text.

Reference to the contingency table has been added.

10. P8, L1: Delete "the absence/presence of", just write "summer precipitation governs ?"

OK

11. P8, L52: What is meant with "sensitivity domain"?

This terminology has now been introduced earlier in this paper (and is used extensively in part 1).

12. P9, L7-16: Consider skipping this sentence, this information is already given before.

This information is not provided previously: the merging of types into families was described earlier (Section 2.1), but not what response surfaces are then used for the merged families.

13. P9, L47ff: Write "climate change projections"; rather than saying how the analysis can be done, formulate the paragraph such that it describes what you have done. I don't understand the "sub-period methodology", either explain better if this is needed or skip.

OK. Section 3.1 is meant to be describing the general application of the full sensitivityexposure-vulnerability method, so this paragraph is formulated as such; Section 3.2 describes our specific application of the method for the two example catchments using CMIP3 scenarios. The term 'sub-period' has been removed.

14. P10, L13: The term "composite" is confusing here. Just say that a flood response surface can be evaluated at values given by a climate change scenario to estimate change in RP20.

$\mathrm{OK}$

15. P10, L45: Does "until recently" imply that there are new regulations in place?

Yes, the Environment Agency released new regional guidelines a year or so ago, based on our work.

16. P11, L40: Specify the future period with its first and last year, e.g. 2071-2100 instead of 2080s.

OK

17. P11, L48: I suggest the following formulation: "The ensemble of exposures is translated to an ensemble of impacts by evaluating the response surface for each value pair $\left(A, X \_0\right.$ ) (Table $3 . "$

$\mathrm{OK}$, the wording has been changed as suggested. 
18. P12, L49 - P13, L55: A discussion of the method to convert changes in mean and amplitude to monthly changes could better be part of paper I which describes the construction of flood response surfaces including the harmonic function.

OK, this discussion has been moved to Part 1.

19. P12, L51: Is there no regional variation for the climate change projections, do you use national averages? I don't understand why a delta change approach would be the only way to apply the same changes for different catchments. Could one not have used a weather generator with fixed changes in means and amplitude for each of the 154 catchments to construct the flood response surfaces? Using climate model outputs indeed would not fit with the flood response surface approach, as these only come in as exposure indicators. This sentence is referring to the fact that the sensitivity framework applies the same sets of delta changes to every catchment - this has been clarified. [Climate change projections are only used in terms of overlaying an exposure on response surfaces, and these are locationspecific.] While it is possible to apply a sensitivity framework using a weather generator (as done by Bastola et al. 2011, Science of the Total Environment, 409), such an approach would introduce noise into the resulting response surfaces, due to different runs of the weather generator being applied at different positions of the sensitivity domain, and hamper our aim of classification and characterisation of response surfaces - this has been clarified in the text (and now moved to Part 1 of this pair of papers, and referred to from this paper, at the request of the editor). To reduce this noise would entail running a large ensemble of weather generator runs at each position of the domain, thus significantly increasing the computational burden. The delta change method was thus the best approach, given our need for consistency in the response surfaces to enable clearer classification and characterisation.

20. P13, L26: Add a reference for the statement that current GCMs do not provide accurate precipitation sums at sub-monthly scale.

Reference provided, in text now moved to Part 1.

21. Fig 1 - is this the correct figure? I cannot see any grey boxes and do not recognize the three stages. This figure is too confusing, what are the different reports, what is the meaning of the different shapes? A flow diagram to illustrate the approach is a good idea, but it should be much simpler than this one and all elements should be explained.

You're right - the incorrect figure was uploaded when the paper was submitted. The correct figure has now been attached and hopefully makes much more sense!

22. Figure 2: in the caption, add the variable that is shown in the response surface, change in 20-year return period flood peak. Also consider adding points for the climate scenarios from Table 3 (see Prudhomme et al. 2010, Fig. 6). This would illustrate how exposure is combined with sensitivity.

The exposure discussed in the text (ECHOG A1B scenario of mean precipitation change of $15 \%$ with a seasonal variation of $15 \%$ ) has been added to the composite response surfaces (mean and standard deviation) to illustrate the methodology. We think that adding all 45 scenarios might detract from comparing varying impact obtained from different response surfaces. 
23. Table 3: Is the GCM output taken from a single grid cell or averaged for larger area? Define the acronyms. Consider skipping the phi-columns, as these values apparently have been set to 1 in the analysis. I suggest to arrange the table with separate columns for ( $A, X_{-} \theta$, Chg, SD) for each SRES and skipping the emission column, the columns would then be "GCM, A2: A, X_ $\theta$, Chg, SD, A1B: A, $X_{-} \theta$, Chg, SD, B1: A, $X_{-} \theta$, Chg, SD". You could also add the ensemble average for each emission scenario. Delete "RCM" from the column names, only GCMs were used?

Table 3 has been reformatted along the lines suggested, although the phi columns have been retained as they give an indication of the appropriateness of the sensitivity framework simplifications. Single GCM grid cells have been used; this has been clarified in the caption, and a reference has been added for GCM and scenario acronyms/definitions. We have not added the ensemble averages for each emission scenario, as we feel these would complicate the table too much and would not be directly comparable between emissions scenarios since there are different numbers of GCMs available for each.

24. Fig 3 and Table 3: Define what the SD represents. Consider highlighting $\mathrm{C}=20$ (e.g. by using a different point symbol or and different colour at $\mathrm{C}=20$ ) and adding the fact that a $+20 \%$ increase in flood peaks has been a politically accepted upper limit.

The figure has been edited as suggested.

25. Supplementary material, Table c: I suggest to use "Simulated flood sensitivity" and "Flood sensitivity according to decision tree" instead of "Observed" and "Attributed".

See response to comment 9 above.

\section{Reviewer \#3:}

I believe the paper may be suitable for publication in Climatic Change, but the authors will need to address some of my comments below.

\section{General comments}

The methodology of characterising the sensitivity of catchments to climate change by creating FRSs is described by Prudhomme et al. (2010) and assumes monthly (or seasonal? see page 3 of the current manuscript) change factors in precipitation and temperature. However, it is by now quite well established that projections of climate change not only involve changes in the amount of precipitation, but also in intensity and variability, this was e.g. one of the findings of the latest assessment report of the IPCC (2007, WG1, chapter 10). This means the authors ignore one aspect of climate change that may be highly relevant to the generation of floods. The discussion section of the current paper seems to suggest this is more or less inherent to the methodology ( $p .13$ : "...practical implementation might be difficult... would significantly increase the complexity of the sensitivity domain..."). As a casual reader or, for that matter, as a policy maker, this may make me wonder whether the current results have any plausibility at all?

Many hydrological climate change impact studies use the change factor approach, so have the same caveats as this one, in terms of not specifically incorporating changes in higher frequency variability or sequencing of events. This feature is acknowledged and discussed in this pair of papers (now at the end of Part 1, at the editor's request). Future work will 
investigate enhancements to the method, but for this first implementation of a generalised sensitivity framework we needed to keep things relatively simple.

Not entirely unrelated to this, the methodology relies on a large number of hydrological simulations in a large number of catchments (as described in Prudhomme et al., 2010). These simulations are done with a hydrological model calibrated (presumably) for each catchment separately using observed river flows. In the sensitivity analysis this model is then applied well beyond the climatic range for which it is calibrated, and also well beyond the range normally studied in climate impact studies (see e.g. Prudhomme et al., 2010, fig.6). Others (e.g. Merz et al., 2011, Time stability of catchment model parameters: Implications for climate impact analyses, Water Resour. Res., 47, W02531, doi:10.1029/2010WR009505) have pointed out this can have a major impact on the results that are obtained. This is particularly relevant as the model that is used here is a lumped conceptual model, which is highly dependent on model calibration. Again, this calls into question the plausibility of any results obtained in the present analysis. It also made me wonder whether some of the catchment properties used to characterise the flood response to climate change are also used in the hydrological model? If that's the case, there might be a circular argument (catchment properties define, in the model, the flood response, which is then linked to the same catchment properties via the decision tree).

The hydrological modelling details are provided in Part 1, and references therein (e.g. Crooks et al. 2009). Two hydrological models were used, one lumped (PDM) and one semidistributed (CLASSIC). Most of the parameters in CLASSIC are derived from catchment properties (all different to those used for the decision trees) so are not dependent on individual catchment calibration and provide spatially-consistent parameters for catchments across Britain, with a wide range of physical and climatic conditions. Calibration of the PDM is catchment specific, but the results were analysed together (one catchment was modelled with both models) and there was no evidence that they were model-specific. Calibration was done, and model performance assessed, over a long period of observed flow record (over 30 years for most catchments) covering a wide range of hydrological conditions (droughts and floods), thus the calibrations are considered robust under a wide range of climatic conditions. Use of the models to simulate recent more extreme floods than in the calibration period has shown good performance.

It is acknowledged that some of the sensitivity domain scenarios are beyond the range of observed conditions, and uncertainty for these is higher than over the parts of the domain associated with less extreme changes to climate variables (shown in the standard deviation for each response surface, Figure 2 of Part 1, where SD is higher over the right-hand half of a surface, where scenarios have more extreme changes in seasonality). However, the analysis of the response surfaces considered only the part of the surfaces with less than $80 \%$ seasonality (i.e. the left-hand $2 / 3$ of the domain, see Part 1 Section 3.2).

Text discussing uncertainty at the end of Section 3.1 has been amended, and now includes specific mention of hydrological modelling uncertainty.

The Supplementary Material contains a hydrological discussion (Section 3 ) which tries to understand the links between catchment properties and flood response from a hydrological (process-based) perspective, which I like very much. Unfortunately this section is not referred to in the main text. I would strongly suggest to include this section in the general discussion (Section 4 of the main paper). (This hydrological discussion raises some comments though, see below). 
The hydrological discussion was moved to supplementary material due to the word count limitations of Climatic Change and the editor's opinion that the original version of the characterisation paper was too hydrological. However, proper reference to this discussion has now been added to the main text. If the editor agrees that this discussion should be moved back to the main text, then we are happy to do that.

Detailed comments

p.3: "...variation in the 'climate-to-impact' signal of change can be systematically quantified for relevant impact variables, difficult in scenario-led approaches..." Is that really so difficult in more traditional impact studies? Note the current framework requires a large number of hydrological simulations as well, and many "scenario-led approaches" nowadays explore a range of scenarios and models. Another question is whether this variation in the signal can indeed be "systematically quantified" across a very wide climatic range by using a calibrated hydrological model, see general comment above.

The co-variation of climate scenarios and catchment properties in traditional top-down impact studies means it is difficult to tell whether simulated differences in impacts are due to differences in the climate scenarios applied or differences in the catchment response to those scenarios. See response to final comment below and response to general comment on hydrological modelling above.

p.3: "A simple cosine function..." Is that what is called "harmonic function" in the 2010 paper?

This phrase has been removed.

p.3: The difference between flood sensitivity "types" and "families" is not immediately obvious, both seem to describe some aggregate or typical response pattern?

See response to comment 4 of reviewer 2 .

p.3: "(i) Neutral. Changes in flood peaks of similar magnitude to maximum monthly $\mathrm{P}$ change..." Presumably the authors are talking about relative changes here, and are not comparing changes in $\mathrm{m} 3 / \mathrm{s}$ to $\mathrm{mm} / \mathrm{month}$.

This has been clarified.

p.5 / Supplementary Material section 1: Some descriptors seem interrelated, e.g. AREA (Catchment drainage area) and DPLBAR (Index describing catchment size and drainage path configuration), and DPLBAR and LDP (Longest drainage path). Does that influence the analysis?

This does not influence the analysis, as we are not using regression.

p.6 / Table 1: the primary discriminator in the decision tree, SAAR (standard period average annual rainfall), as well as other catchment "properties" that were included (e.g., RMED (Median annual maximum rainfall), SMDBAR (Mean soil moisture deficit) or PROPWET (Index of proportion of time soils are wet)) are strictly speaking not static properties but climatic variables that are presumably expected to change. I can see the logic of describing the current "wetness" of a catchment, but this aspect may require some more explanation. Text has been added in the Supplementary material to clarify use of climatic properties and other catchment properties which have values which may change over time. 
p.7: "...compares the observed (modelled) and attributed FSFs..." Observed is very unfortunate wording in what is entirely a model-based analysis. See response to comment 9 of reviewer 2 .

p.7: "River flow regime is known to be dependent on catchment properties..." But here a rather liberal interpretation of "catchment properties" is used, not just soil and topography but also climatic variables that are bound to change, see previous comment.

See response to point on p.6/Table 1 above.

p.8 / Figure 1: ""The grey box is not fully implemented here..." Sorry, I can't see any grey box. The figure contains boxes for producing "reports", giving the impression it was lifted straight from a project proposal.

See response to comment 21 of reviewer 2 .

p.8: "The latter only relies on the availability of certain catchment properties..." But the latter method is ONLY possible once a sensitivity analysis (as in Prudhomme et al., 2010) has been performed in a large set of catchments, and the results analysed in relation to the catchment properties (as in the current paper). It's not that we can apply the British flood sensitivity characterisation to, say, an ungauged catchment in Africa. I feel the authors are overselling the ease of applying their "screening tool" to "ungauged or unmodelled catchments". In reality, there is a large number of prerequisites involving a large number of simulations in a large number of catchments requiring a huge amount of data that may not be so readily available elsewhere.

The sentence has been changed. See response to final comment below.

p.12: "For the Dove, 11 out of 45 scenarios (24\%) have a composite RP20 change greater than the current $20 \%$... For the Cole, only 6 scenarios (13\%) have a composite RP20 change greater than $20 \%$..." This is counterintuitive as the Dove is classified as "Neutral" in Table 3, while the Cole is "Sensitive". Text has been added to clarify why, in this example, the Cole has fewer scenarios than the Dove with RP20 change greater than $20 \%$.

p.13: "...the latest generation of Climate Models (from CMIP3 for example)..." CMIP3 is not quite the "latest" set of climate simulations available.

OK, this sentence has been changed.

p.13: "...are not yet able to reproduce accurately sub-monthly precipitation sequencing..." I'm not sure what the authors mean here. Surely that doesn't mean you can conveniently ignore projected changes in precipitation intensity or variability (which are based on physical insight as much as simulations)? It's a strange argument especially in the light of the authors' claims that their methodology is "scenario-neutral" and does not depend on climate simulations to assess the sensitivity of a catchment.

See response to first General Comment.

Supplementary section 3, p.6: "Up to now, the role of the catchment in its response to climatic change has often been neglected in climate change impact studies and adaptation planning compared to the climate change signal itself..." I would argue this is not true, and probably unfair to others. In many studies it is implicitly included, for example through the formulation (or calibration) of the impact model. And I think it is certainly not true 
that traditional impact studies haven't looked at "different processes shaping the response of a system to climatic change".

The original wording was not meant to imply that the role of the catchment is not included in impact studies, but that its particular influence is often not been specifically investigated (see response to first p.3 comment above); the sentence has been reworded to help clarify the meaning.

Supplementary section 3, p.6: "As most studies are based on few catchments, generalising their results is problematic..." But how easy can the current results be generalised to other countries or regions of the globe? It would seem the current method is highly dependent on a number of nationally defined (and available) set of catchment properties. And presumably it is also highly (impact) model dependent, which is another aspect not explored by the authors. While it is quite true that our response surfaces and decision trees cannot be applied to catchments in other countries, they can be applied to many catchments in Britain for which we currently have little idea about the impacts of climate change on flooding (e.g. over 1400 catchments listed in the National River Flow Archive). Furthermore, setting up the response surfaces and decision trees is in fact relatively straightforward, if initially computationallydemanding. While derivation/use of decision trees does need nationally-available catchment property data, such data (e.g. from DTMs, satellites etc) are likely to be more readily available than the long series of gauged flows required for robust calibration of a hydrological model. Once setup, the framework means that it is then easy to apply new sets of scenarios for a great number of catchments. A follow-up paper will demonstrate this by applying sets of 10,000 climate change scenarios (from UKCP09) across Britain. 
Click here to download Manuscript: Climate change and river flooding_Part2_Characterisation and Vulnerability_Revised_NoEndnote Click here to view linked References

\title{
CLIMATE CHANGE AND RIVER FLOODING: PART 2 SENSITIVITY CHARACTERISATION FOR BRITISH CATCHMENTS AND EXAMPLE VULNERABILITY ASSESSMENTS
}

Christel Prudhomme, Alison L. Kay, Sue Crooks, Nick Reynard

Short title: Characterising the sensitivity of British flood flows to climate change

Revised for Climatic Change, February 2013

Corresponding author: Christel Prudhomme, Centre for Ecology and Hydrology, Wallingford, Oxfordshire, OX10 8BB, United Kingdom. Email: chrp@ceh.ac.uk ; Telephone: +44 (0)1491 692381

\begin{abstract}
This paper is the second of a series describing a scenario-neutral methodology to assess the sensitivity and vulnerability of British catchments to changes in flooding due to climate change. In paper one, nine flood sensitivity types were identified from response surfaces generated for 154 catchments. The response surfaces describe changes in 20-year return period flood peaks (RP20) in response to a large set of changes in precipitation, temperature and potential evapotranspiration. In this paper, a recursive partitioning algorithm is used to link families of sensitivity types to catchment properties, via a decision tree. The tree shows $85 \%$ success characterising the four sensitivity families, using five properties and nine paths. Catchment annual average rainfall is the primary partitioning factor, with drier catchments having a more variable response to climate (precipitation) change than wetter catchments and higher catchment losses and permeability being aggravating factors. The full sensitivityexposure-vulnerability methodology is illustrated for two catchments: sensitivity is estimated by using the decision tree to identify the sensitivity family (and its associated average response surface); exposure is defined from a set of climate model projections and combined with the response surface to estimate the resulting impacts (changes in RP20); vulnerability under a range of adaptive capacity thresholds is estimated from the set of impacts. Even though they are geographically close, the two catchments show differing vulnerability to climate change, due to their differing properties. This demonstrates that
\end{abstract}


generalised response surfaces characterised by catchment properties are useful screening tools to quantify the vulnerability of catchments to climate change without the need to undertake a full climate change impact study.

\section{Keywords}

Discriminant analysis; Sensitivity; Hydrological processes; Response surface; Flood risk; Vulnerability; 


\section{Introduction and background}

With growing scientific consensus on global warming (IPCC, 2007a, b), research studies to investigate its potential impacts on ecosystems and adaptation strategies have multiplied (Wilby et al., 2009). The majority assess the impact of specific climate change scenarios usually derived from Global/Regional Climate Model (G/RCM) projections - but when new model variants emerge such scenario-led impact studies also require updating.

A new approach to climate change impact assessment has recently emerged based on a 'bottom-up' approach aiming to identify the vulnerability of an environmental system to climatic risk (Pielke and Bravo de Guenni, 2004). The approach is based on a sensitivity analysis to derive response surfaces against which different adaptation thresholds can be evaluated, making it effectively 'scenario-neutral'. When included in an adaptation planning framework, the vulnerability assessment can be repeated with different sets of scenarios and adaptive capacity thresholds, providing the evidence necessary for decision makers (Wilby and Dessai, 2010).

By implementing the same fixed scenario-neutral sensitivity framework and generating the corresponding response surfaces for a range of catchments, variation in the 'climate-toimpact' signal of change can be systematically quantified for relevant impact variables, difficult in scenario-led approaches (Wilby et al., 2008). Recently, a scenario-neutral framework was developed to assess the sensitivity of flood peaks to climate change in Britain (Prudhomme et al., 2010), using a sensitivity domain comprising 4200 combinations of changes in precipitation (P), temperature $(T)$ and potential evapotranspiration (PE). In part 1 (Prudhomme et al., submitted)this sensitivity framework was applied to 154 catchments using hydrological modelling, resulting in flood response surfaces illustrating changes in 2-, 10- and 20-year return period flood peaks for each catchment (Prudhomme et al., submitted, Section 2.4). Nine flood sensitivity types were shown to summarise the different ways in which the study catchments propagate the 'climate-to-flood' signal of change, each with a composite (average) response surface (Prudhomme et al., submitted, Section 3.2). These nine sensitivity types describe five main families of catchment flood responses found in Britain: 
(i) Neutral. Percentage changes in flood peaks of similar magnitude to maximum monthly $\mathrm{P}$ percentage change;

(ii) Damped. Percentage changes in flood peaks of similar magnitude or generally lower than maximum monthly $\mathrm{P}$ percentage change. Flood regime relatively insensitive to small P increases;

(iii) Enhanced. Percentage changes in flood peaks of similar magnitude or generally greater than maximum monthly $\mathrm{P}$ percentage change. Flood regime affected even by small P increases;

(iv) Sensitive. Percentage changes in flood peaks very dependent on the precise characteristics of $P$ changes - a small increase in $P$ may lead to a much greater increase in flood peaks;

(v) Mixed. Percentage changes in flood peaks mixed (damped/neutral/enhanced) depending on magnitude and seasonal pattern of $\mathrm{P}$ changes. Catchments particularly affected by summer $P$ increases.

Note that these names describe how flood peaks change relative to the maximum monthly $\mathrm{P}$ change; they do not describe how a catchment responds to $\mathrm{P}$ as an input.

Catchment properties influence streamflow generation processes and the response of river flows to change in climate (Fu et al., 2007). This paper investigates whether sensitivity types and catchment properties are linked, enabling such properties to be used to associate a sensitivity type, and corresponding composite response surface, to any catchment (including unmodelled or ungauged). This further enables an assessment of vulnerability for such catchments, without the need to undertake a full climate change impact study with a local impact model, by overlaying exposure and sensitivity. This sensitivity-exposurevulnerability approach could thus be used as a screening tool for a large number of catchments (for example, the UK National River Flow Archive, www.ceh.ac.uk/data/nrfa, lists over 1400 catchments in Britain).

A decision tree approach is used to establish a characterisation of sensitivity types by catchment properties (Section 2). Section 3 describes the application of the full sensitivityexposure-vulnerability approach and presents an example vulnerability assessment for two catchments, using composite response surfaces and sets of climate change scenarios, and 
illustrates how vulnerability and risk diagrams can help compare different adaptive capacity thresholds and catchment responses. Section 4 discusses the overall approach, with conclusions in Section 5.

\section{Sensitivity characterisation}

Relationships between flood sensitivity to climatic changes and catchment properties are investigated using a recursive hierarchical partitioning technique (Ripley, 1996). The decision trees resulting from this discriminant analysis are easy to interpret (Wei and Hsu, 2008) and can be adapted to expert knowledge approaches (Wang et al., 2009). Being nonparametric, they do not require assumptions on the distribution of the input data (Wang et al., 2009); advantageous for environmental data. Results are presented using the sensitivity for the 20-year return period flood peak (RP20).

\subsection{Data}

Nine sensitivity types were identified from the study catchments (Prudhomme et al., submitted); Damped-Extreme, Damped-High, Damped-Low, Neutral, Mixed, Enhanced-Low, Enhanced-Medium, Enhanced-High, Sensitive. Because the sample available for the Damped-Extreme type is too small (three catchments) to allow reliable characterisation, the corresponding catchments are removed from the sample, leaving eight types (151 catchments).

The sensitivity types emerged from analysing changes in flood peaks resulting from $\mathrm{P}$ change scenarios with a smoothed variation through the year, peaking in January (Prudhomme et al., submitted, Section 2.3). The effect of the month of the maximum $P$ change was investigated by Kay et al. (2009) who found that for catchments with Damped types, the response surface may be either less damped or Neutral when peak $\mathrm{P}$ changes occur in autumn, while for catchments with Enhanced types the response surface may be further enhanced. When the peak $P$ change occurs between February and mid-summer, the effect on changes in flood peaks is generally less. In order to integrate this variation in response surfaces due to the month of maximum $P$ changes, and to address the issue of the small size of the groups for some types (which is a problem for the recursive partitioning 
algorithm), the remaining eight sensitivity types for RP20 are merged as follows: Neutral with Damped-High and Damped-Low; Enhanced-High with Enhanced-Medium and Enhanced-Low; Mixed and Sensitive remain unchanged. Four flood sensitivity families are thus used at RP20 (Neutral/Damped, Mixed, Enhanced, and Sensitive, in approximate order of increasing response variability).

Two main sources of catchment properties are available digitally in Britain: the Flood Estimation Handbook (FEH; Reed, 1999) and the National River Flow Archive (NRFA) Hydrometric Register (Marsh and Hannaford, 2008). After a preliminary analysis, a subselection of $27 \mathrm{FEH}$ and NRFA properties is used in the discriminant analysis of sensitivity families, including information on catchment area, altitude, aspect and permeability (Supplementary Section 1).

\subsection{Principles of decision trees and model complexity}

A decision tree divides the space of possible observations (catchments) into sub-regions of the same category (sensitivity family) according to descriptors (catchment properties). It is an iterative approach: (i) The root is the top node (full sample); (ii) data at each node are split into two branches by binary tests (rules) to form two child nodes; (iii) a node becomes a leaf when no further split is possible or relevant; (iv) each leaf is associated with a probability for each sensitivity family; ( $v$ ) a leaf is reached by following a set of rules (path). Decision trees thus enable the use of catchment metadata to assign a sensitivity family to a catchment (generally the family with the highest probability for the appropriate leaf). Imposing a maximum number of leaves or 'pruning' the tree by aggregating leaves are two common ways to reduce complexity. Cross validation, evaluation using contingency tables (Jolliffe and Stephenson, 2003) and expert judgment help define the final decision tree:

- At least one path/leaf attributing each sensitivity family;

- Each leaf should be as pure as possible, but if a leaf contains catchments from different families they should not have very different sensitivity;

- Paths should describe logical hydrological processes;

- The tree should not have too many small splits leading to a large number of leaves; 
- Hit rate (family assigned by the decision tree the same as that simulated with the hydrological model) maximised, but misses (assigned family of lower response variability than simulated) minimised; false alarms (assigned family of higher response variability than simulated) are of lesser concern than misses. This does not take priority over the existence of a path for each sensitivity family and the logic of the hydrological processes.

The $\mathrm{R}$ freeware package tree and the commands (default options) tree, $\mathrm{CV} \cdot \mathrm{tree}$ prune.tree and predict.tree are used.

\subsection{Characterisation results}

The discriminant analysis results in a decision tree (Table 1 ) that characterises the RP20 sensitivity families using nine paths and five catchment properties; standard average annual rainfall for 1961-1990 (SAAR, mm), catchment area (Area, $\mathrm{km}^{2}$ ), northing of catchment outlet (North, GB national grid reference), percentage of high permeability bedrock (BHP, \%) and mean annual loss (MAL, mm; the difference between mean annual rainfall and runoff). Two of the selected catchment properties, SAAR and MAL, are climatic variables which may change with time, therefore values are used for a specified period representing current conditions. The probability of each family is provided for each path (Table 1): paths are rarely associated with a highest probability of one but for most paths the majority of catchments generally belong to the same family (i.e. highest probability greater than 0.5 ). For each path an indicator of confidence in the highest probability family is also given, categorised as High (H), Medium (M), or Low (L). This indicator combines 'certainty' and 'robustness', where certainty is the difference between the two top probabilities for the path and robustness is the percentage of the original sample following the path (Supplementary Section 2).

Table 1. (place holder)

Performance of the decision tree is quantified using a contingency table (Jolliffe and Stephenson, 2003) which compares the simulated and assigned sensitivity families of the study catchments (Supplementary Table c). Overall, $85 \%$ of catchments are correctly 
classified, with $15 \%$ misclassified. Out of $6.6 \%$ false alarms, $4.6 \%$ have a higher response variability by only one category (e.g. simulated Neutral/Damped but assigned Mixed, or simulated Enhanced but assigned Sensitive). Out of $8.6 \%$ misses, $7.2 \%$ have a lower response variability by only one category.

River flow regime is known to be dependent on physical and climatic catchment properties; some sensitivity families are associated with several paths, showing that different combinations of catchment properties can represent catchments with similar response surfaces. The decision tree in Table 1 characterises the four sensitivity families associated with changes in RP20, but decision trees were also built for the nine sensitivity types for changes in 2- and 10-year return period flood peaks (RP2 and RP10; Reynard et al. (2009)). Using the decision trees that characterise the sensitivity type or family for the three flood indicators (RP2, RP10 and RP20) it is possible to highlight the dominant characteristics associated with each (Supplementary Table d). Two catchment properties are found to be key factors in the partitioning of the decision trees: SAAR (first split for all three indicators) and BHP. Area and the relative values of SAAR and MAL are also recurrent properties in many paths. MAL is particularly important for Mixed, Enhanced and Sensitive catchments, with Sensitive catchments associated with high MAL. This highlights that features of the annual water balance characterise a catchment's response to the climatic signal. In dry catchments, summer precipitation governs the build-up of soil moisture deficits which influences the recharge capacity and catchment saturation level of wetter seasons. These factors reflect the complex hydrological processes resulting in soil moisture variation generating higher variability in runoff coefficient than rainfall variation. Note however that these are guidelines only; a catchment does not necessarily have the same sensitivity type for all indicators, and more catchments have Damped types for higher frequency (e.g. RP2) than lower frequency (e.g. RP20) flood peaks. An extended hydrological discussion of sensitivity types/families is provided in Supplementary Section 3.

\section{Vulnerability assessment using the scenario-neutral approach}

The assessment of vulnerability to climate change from the scenario-neutral framework involves a three-stage process (Figure 1): 
Stage 1 - Sensitivity: Determine the response of a catchment's flood regime to climate change.

Stage 2 - Exposure: Quantify the future climate change projections to which the catchment may be exposed.

Stage 3 - Impacts and vulnerability: Calculate the impacts (flood changes), by combining the sensitivity and exposure of the catchment. Compare the impacts to an adaptive capacity threshold (e.g. the maximum change against which the catchment is currently protected) to define catchment vulnerability.

Figure 1. (place holder)

This section describes these stages and presents example applications for two catchments.

\subsection{Step-by-step methodology}

\section{Stage 1 - Sensitivity}

A catchment's sensitivity type/family can be determined either through a modelling study using this sensitivity domain (Prudhomme et al., 2010) or from a flood sensitivity classification and characterisation using catchment properties (Section 2). The former analysis requires an impact model and is computationally demanding, but provides a catchment-specific response surface. The latter relies on the availability of certain catchment properties and is simple to implement, but links the catchment with a generic sensitivity type/family and its associated composite response surface, hence introducing additional uncertainty.

When no impact model exists for the considered catchment, the decision tree for changes in RP20 (Table 1) assigns one of four sensitivity families based on five catchment properties. Note that after the regrouping of eight sensitivity types into four families (Section 2.1), the Neutral composite response surface (and its standard deviation surface) is associated with the Neutral/Damped family and the Enhanced-High composite response surface (and its standard deviation surface) is associated with the Enhanced family, so that possible underestimation of changes in flood peaks using the response surfaces of sensitivity families is minimised. 
Decision trees provide the probability for a catchment with a set of properties to belong to each of the four sensitivity families, and an indicator of confidence (High- $\mathrm{H}$, Medium-M or Low-L) in the best-estimate. For larger catchments (Area $>1000 \mathrm{~km}^{2}$ ) it is recommended that the confidence for the corresponding decision tree path be reduced by one level $(\mathrm{H}$ to $\mathrm{M}$ and $M$ to $L$ ), as large catchments are less well represented by catchment-average properties. For paths associated with $\mathrm{M}$ or $\mathrm{L}$ confidence, it is recommended that all families associated with high probabilities are considered when undertaking the impact and vulnerability assessments. Similarly, if one (or more) of the properties for a given catchment is close to one of the thresholds in the decision tree, it is recommended that the families from the alternative path(s) are also considered. Considering several possible sensitivity families for a single catchment is a way to account for some of the uncertainty introduced by the classification and characterisation procedures.

\section{Stage 2 - Exposure}

The exposure relates to the climatic changes the catchment may be exposed to for a given time horizon. Future climate change projections (e.g. GCMs/RCMs) are possible ways to define the exposure of a catchment for a given future time horizon. The monthly change factors associated with climate model projections can be derived from time series representative of current and future climate time slices, possibly using the resampling methodology suggested in Prudhomme et al. (2010).

For consistency between exposure and the sensitivity domain of the response surfaces, the monthly climate change factors of the exposure are described as a mean annual change $\left(X_{0}\right)$ and seasonal amplitude $(A)$ by fitting a single-phase harmonic function. The two parameters $\left(X_{0}, A\right)$ are expressed as the nearest multiple of $5 \%$ (the resolution of the sensitivity domain); the phase $\Phi$ is ignored as the sensitivity domain assumes $\Phi=1$ (January) (see Prudhomme et al., submitted, Section 2.3).

\section{Stage 3 - Impacts and vulnerability}

For any response surface, the impact of an exposure is the RP20 change corresponding to the scenario of the sensitivity domain that is most similar to the exposure (i.e. the exposure can be overlaid on the response surface). If changes in T are known, the response surface using the closest of the eight T/PE scenarios of the sensitivity domain could be considered. 
Alternatively, impacts from all eight T/PE response surfaces can be considered, either separately or as an average. The latter approach is used here, as changes in T were shown to be generally much less important than changes in P (Prudhomme et al., submitted, Section 3.3).

When using a composite response surface, the uncertainty resulting from considering that surface instead of a modelled catchment response surface can be added by using the standard deviation (SD) surface associated with the composite surface (Prudhomme et al., submitted). Additional uncertainty, for example linked to hydrological model uncertainty (e.g. Bastola et al., 2011) or use of response surfaces instead of direct hydrological modelling under climate change (Kay et al., 2009), could also be investigated and included. Such uncertainty will be the subject of a future paper; in the following, only uncertainty due to use of composite response surfaces to represent a range of modelled response surfaces is considered.

Vulnerability is here defined as the degree to which a system is unable to cope with a certain change, using a given adaptive capacity threshold $C$. For individual catchments, the degree of vulnerability $v(C)$ is the likelihood of a set of exposures resulting in an impact greater than $C$. For flood risk in Britain, an adaptive capacity $C$ was (until recently) quantified as a $20 \%$ increase in flood peaks (Department for Environment Food and Rural Affairs, 2006).

\subsection{Examples of implementation}

The vulnerability assessment method is applied to two contrasting catchments: the Dove at Rocester Weir (NRFA catchment number 28008) and the Cole at Coleshill (NRFA 28066) both in the Midlands region of England (Table 2). The following assumes the catchments have not been modelled using the sensitivity framework (although they have).

Table 2. (Place holder)

\section{Stage 1 - Sensitivity: Determine the flood response surface}

Using their catchment properties (Table 2), the Neutral/Damped family is associated with the Dove at Rocester Weir (path 7 of Table 1; High confidence) and the Sensitive family is 
associated with the Cole at Coleshill (path 6 of Table 1; Medium confidence). Each composite response surface is assumed representative of the modelled catchment response surface; Figure 2 shows good similarity between the Dove local response surface and the Neutral composite surface (top) and between the Cole local response surface and the Sensitive composite surface (bottom). The standard deviation (SD) surfaces (Figure 2, right) provide information on the uncertainty associated with each composite response surface. Note the much larger SD associated with the Sensitive surface than the Neutral surface.

Figure 2. (place holder)

\section{Stage 2 - Exposure: Determine the harmonic function parameters for the required climate change scenario(s)}

Using monthly time series projections from CMIP3 obtained from the IPCC Data Distribution Centre (http://cera-www.dkrz.de/CERA/index.html) and the Program for Model Diagnosis and Intercomparison (PCMDI, http://www-pcmdi.llnl.gov), an ensemble of exposures is defined by fitting a single-phase harmonic function to monthly precipitation change factors for each projection as in Prudhomme et al. (2010) (Table 3). The exposures are defined for the 2080s time horizon (2071-2100).

Table 3. (Place holder)

\section{Stage 3 - Impacts and vulnerability: combining flood sensitivity and exposure}

The ensemble of exposures is translated to an ensemble of impacts, by extracting the percentage change from the appropriate response surface (and corresponding SD surface) for each exposure pair $\left(A, X_{0}\right)$ (Table 3 ). For example, for the Dove the exposure ECHOG under $\mathrm{A} 1 \mathrm{~B}$ emissions represents an annual precipitation increase $\left(X_{0}\right)$ of $15 \%$ and a seasonal amplitude $(A)$ of $15 \%$, which corresponds to an impact of $+29 \%$ from the Neutral composite surface (Figure 2); considering the uncertainty in the composite surface to be quantified by twice the SD $(2 \%)$, the impact range is $24-32 \%(28 \pm 2 \times 2 \%)$. For the Cole, ECHOG under A1B has an RP20 impact range of $-9-83 \%(37 \pm 2 \times 23 \%)$.

For the Dove, 11 out of 45 scenarios (24\%) have a composite RP20 change greater than the current 20\% climate change allowance for England and Wales, rising to 16 scenarios (36\%) when adding $2 *$ SD. For the Cole, only 6 scenarios (13\%) have a composite RP20 change 
greater than $20 \%$, but this rises to 29 (64\%) when adding $2 *$ SD. Although the Cole belongs to the Sensitive family, compared with Neutral/Damped for the Dove, this does not automatically imply that the catchment is more vulnerable to change; it depends on the scenarios being considered and where these lie on the different response surfaces (see Figure 2 for the differences in alignment and band width of these surfaces).

This example shows that two catchments geographically close to each other but with different catchment properties can have different impacts under the same exposure due to their different sensitivity to precipitation changes, and have different uncertainty associated with the estimated impacts also due to their different sensitivity and to the representativeness of the composite response surface. As a consequence, the vulnerability to the same adaptive capacity threshold $C$ also varies; a national allowance (here $C=20 \%$ ) leaves some catchments more vulnerable than others. Figure 3 shows vulnerability curves (i.e. vulnerability to different $C$ ) for the two example catchments, derived using the impacts from Table 3. Catchments which are geographically distant could also have very different exposures, due to the geographical variation of climate model projections, leading to potentially differing vulnerability even for catchments with similar sensitivity (not shown).

Figure 3. (place holder)

\section{Discussion}

The methodology presented in this two-part series of papers is based on a number of assumptions and a relatively large amount of information - but is still limited in a number of ways. A number of these limitations relate to the sensitivity framework's use of monthly change factors (smoothed using a single-harmonic function) applied to baseline climate data and used to drive a hydrological model; these are discussed in Part 1 (Prudhomme et al., submitted). Further caveats associated with the methodology are discussed below.

The flood sensitivity classification (Prudhomme et al., submitted) and characterisation (Section 2) were established using relatively natural catchments, hence with limited urbanisation or water management practices. This means that the resulting decision trees are not necessarily suitable for catchments where water bodies significantly attenuate river flow, or with a relatively large urbanised area (where infiltration might be reduced and 

hydrological modelling to allow for the influence of snowfall and subsequent melt on runoff. However, the derived decision trees (for RP2, 10 and 20) do not include properties which directly relate to influence of snow on changes to flood peaks. This probably reflects the fact that snowmelt-affected peaks do not dominate the flood regime of the modelled catchments, though many catchments include snowmelt events in their POT series. Supplementary Table d shows which sensitivity types can include decreases in flood peaks due to precipitation as snow and subsequent gradual melt. Such catchments may show variation in response surface with temperature scenario. In other climatic regimes properties relating to snowmelt could have more widespread impact on changes to flood peaks (e.g. Köplin et al., 2012).

Finally, the complete scenario-neutral framework and its implementation for vulnerability assessment are based on two generalisations, both associated with their own uncertainty. First, using the composite response surface of a given sensitivity type/family as a proxy for the catchment response surface will inevitably modify any impact estimate. Second, the flood sensitivity estimation method relies on how well catchment properties summarise the complex hydrological processes, and how many catchments of each sensitivity type/family are represented by the study sample. While uncertainty associated with both generalisations has been investigated, and recommendations made when high uncertainty has been identified, the application of the complete regionalised methodology cannot be 
considered equivalent to an in-depth, detailed climate change impact study based on local modelled impacts from a large range of exposures.

\section{Conclusions}

This two-part series of papers has described the development of a scenario-neutral framework that can be used as a powerful tool to assess the vulnerability to climate change exposure against an adaptive capacity threshold. While the overall methodology was implemented for the impacts of climate change on peak river flows in Britain, it could be transferred to any environmental system for which an impact model can be applied and drivers of change (e.g. climate, land-use or population changes etc.) expressed relatively simply.

Following the definition of vulnerability suggested by IPCC (2007a), the method is based on a three-stage procedure defining sensitivity, exposure, and vulnerability relative to an adaptive capacity. Using a sensitivity domain guided by, but not limited to, climate model projections, the method enables the assessment of the response of catchments to an extensive range of possible exposures. Three novel elements have been introduced within the scenario-neutral framework and explicitly integrated into the vulnerability assessment procedure for the first time:

- Climate change exposure. The uncertainty in climatic change signal as simulated by GCMs and RCMs is known to be large, especially for $P$, which is particularly influenced by the spatial scale of climate models and large climate variability. When climate variability is considered in estimating the mean monthly signal of changes, the range of estimates in the change factors can also be very large. Prudhomme et al. (2010) showed that in the UK, a single-phase harmonic function could summarise in three parameters the possible mean monthly change factors that would be obtained when considering climate variability.

- Sensitivity to seasonality of change. In hydrology, the length and associated total P of wet and dry seasons is important for hydrological processes as generated runoff depends not only on P but also on the soil capacity to absorb more water. The study of the response of different catchments to different seasonal patterns of changes - 
from uniform throughout the year to a large difference in magnitude between wetter and dryer periods - has demonstrated the role of seasonal change and its necessity in sensitivity studies in hydrology.

- Characterisation of flood sensitivity to climate change. The study of the flood sensitivity of 154 catchments across Britain to climate change has shown that the physical and climatic properties of catchments can discriminate their capacity to 'damp' or 'enhance' the climate change signal. The resulting characterisation, based on five catchment properties, enables the assignment of a flood sensitivity family for changes in 20-year return period flood peaks to any catchment in Britain with the appropriate properties, without the need to undertake a systematic sensitivity analysis. This, in turn, enables easy impact and vulnerability assessments. The characterisation has been demonstrated here for 20 -year return period flood peaks, but has also been determined for 2- and 10-year return periods (Reynard et al., 2009).

Combining these three features has delivered a scenario-neutral framework offering a powerful screening tool (similar to the 'risk screening' tier mentioned by Dessai et al., 2005) to rapidly estimate the impacts resulting from a set of exposures and to quantify the associated vulnerability for different adaptive capacity thresholds. Such analyses can be rapidly updated when any new sets of climate change projections are released, without the need to undertake a complex sensitivity study or top-down impact analysis, which is a real advance as it greatly reduces the computing load after the initial study.

Because the framework is applicable to any catchment in Britain, vulnerability assessments can be readily made for a range of scales (from local to national) but also targeted to different sensitivity types/families or catchment properties, highlighting more vulnerable sets of catchments. Once the response surface of each catchment in an area of interest is available, impacts can be estimated by combining the climate change exposure of each catchment with its response surface, and vulnerability under a range of adaptive capacities can be assessed. When numerous scenarios of exposure and catchments are considered, an overall vulnerability assessment (risk level) can be made for the area of interest (regional or national) by counting the proportion of cases when the resulting impact is above a certain 
adaptive capacity threshold $C$. This enables the development of climate change allowances by region or sensitivity type/family, instead of a national allowance.

Note however that the sensitivity analysis presented here does not replace complex climate change impact analysis. For catchments less represented by the study sample (large water body area, heavily urbanised), those showing high variability of flood response to precipitation change (e.g. enhanced and sensitive families) and those associated with a lower confidence level and high uncertainty, it is recommended to undertake a full local climate change impact analysis. Later papers will assess the uncertainty associated with the full approach, and present national and regional vulnerability assessments for Britain.

\section{Acknowledgements}

The work presented in these papers was funded by Defra and the Environment Agency for England and Wales (FD2020 'Regionalised impacts of climate change on flood flows' and follow-up project FD2648 'Practicalities for implementing regionalised allowances for climate change on flood flows') with additional contribution from the NERC-CEH Water science programme. They are all gratefully acknowledged. The development of the science benefited from helpful support from the project managers (Karl Hardy, Ella Thomason and Bill Donovan) and fruitful discussions with Prof. Rob Wilby, as well as from review by Prof. Nigel Arnell and Prof. Howard Wheater. Data were from CMIP3, CERA, IPCC-DDC, FEH and the UK National River Flow Archive. The views expressed are those of the authors and not of the funding organisations.

\section{References}

Bastola S, Murphy C, Sweeney J (2011) The sensitivity of fluvial flood risk in Irish catchments to the range of IPCC AR4 climate change scenarios. Science of the Total Environment 409:5403-5415.

Department for Environment Food and Rural Affairs (2006) Flood and Coastal Defence Appraisal Guidance FCDPAG3 Economic Appraisal - Supplementary Note to Operating Authorities - Climate Change Impacts October 2006. London, p. 9.

Dessai S, Lu X, Risbey JS (2005) On the role of climate scenarios for adaptation planning. Global Environmental Change Part A 15:87-97. 
Fu G, Charles SP, Chiew FHS (2007) A two-parameter climate elasticity of streamflow index to assess climate change effects on annual streamflow. Water Resources Research 43.

IPCC (2007a) Climate Change 2007: Impacts, Adaptation and Vulnerability. Contribution of Working Group II to the Fourth Assessment Report of the Intergovernmental Panel on Climate Change. Cambridge University Press, Cambridge, United Kingdom.

IPCC (2007b) Climate Change 2007: The Physical Science Basis. Contribution of Working Group I to the Fourth Assessment Report of the Intergovernmental Panel on Climate Change. Cambridge University Press, Cambridge, United Kingdom and New York, NY, USA.

Jolliffe IT, Stephenson DB (eds.) (2003) Forecast verification - a practitionner's guide in atmospheric science, John Wiley \& Sons, Chichester, p. 240.

Kay A, Crooks SM, Prudhomme C (2009) Regionalised impacts of climate change on flood flows: uncertainty analysis. R\&D milestone report FD2020/MR5. Joint Defra/EA Flood and Coastal Erosion Risk Management R\&D Programme. Centre for Ecology and Hydrology, Environment Agency, Defra, p. 81.

Köplin N, Schädler B, Viviroli D, Weingartner R (2012) Relating climate change signals and physiographic catchment properties to clustered hydrological response types. Hydrol. Earth Syst. Sci. 16:2267-2283.

Marsh TJ, Hannaford J (eds.) (2008) UK Hydrometric Register, Centre for Ecology and Hydrology, Wallingford, p. 210.

Pielke RA, Bravo de Guenni L (eds.) (2004) How to evaluate vulnerability in changing environmental conditions - Part E, Springer, p. 482-544.

Prudhomme C, Crooks SM, Kay AL, Reynard NS (submitted) Climate change and large river flooding: part 1 classifying the sensitivity of British catchments. Clim. Change.

Prudhomme C, Wilby LR, Crooks SM, Kay AL, Reynard NS (2010) Scenario-neutral approach to climate change impact studies: application to flood risk. Journal of Hydrology 390:198209.

Reed D (1999) Flood Estimation Handbook - Overview. Institute of Hydrology, Wallingford.

Reynard NS, Crooks S, Kay AL, Prudhomme C (2009) Regionalised impacts of climate change on flood flows. R\&D Technical Report FD2020/TR. Joint Defra/EA Flood and Coastal Erosion Risk Management R\&D Programme. Centre for Ecology and Hydrology, Environment Agency, Defra, p. 123.

Ripley BD (1996) Pattern recognition and neural networks. Cambridge University Press, Cambridge.

Wang C, Meer Pvd, Peng M, Douven W, Hessel R, Dang C (2009) Ecosystem Services Assessment of Two Watersheds of Lancang River in Yunnan, China with a Decision Tree Approach. AMBIO: A Journal of the Human Environment 38:47-54.

Wei C-C, Hsu N-S (2008) Derived operating rules for a reservoir operation system: Comparison of decision trees, neural decision trees and fuzzy decision trees. Water Resour. Res. 44:W02428. 
Wilby RL, Beven KJ, Reynard NS (2008) Climate change and fluvial flood risk in the UK: more of the same? Hydrological Processes 22:2511-2523.

Wilby RL, Dessai S (2010) Robust adaptation to climate change. Weather 65:180-185.

Wilby RL, Troni J, Biot Y, Tedd L, Hewitson BC, Smith DM, Sutton RT (2009) A review of climate risk information for adaptation and development planning. International Journal of Climatology 29:1193-1215. 


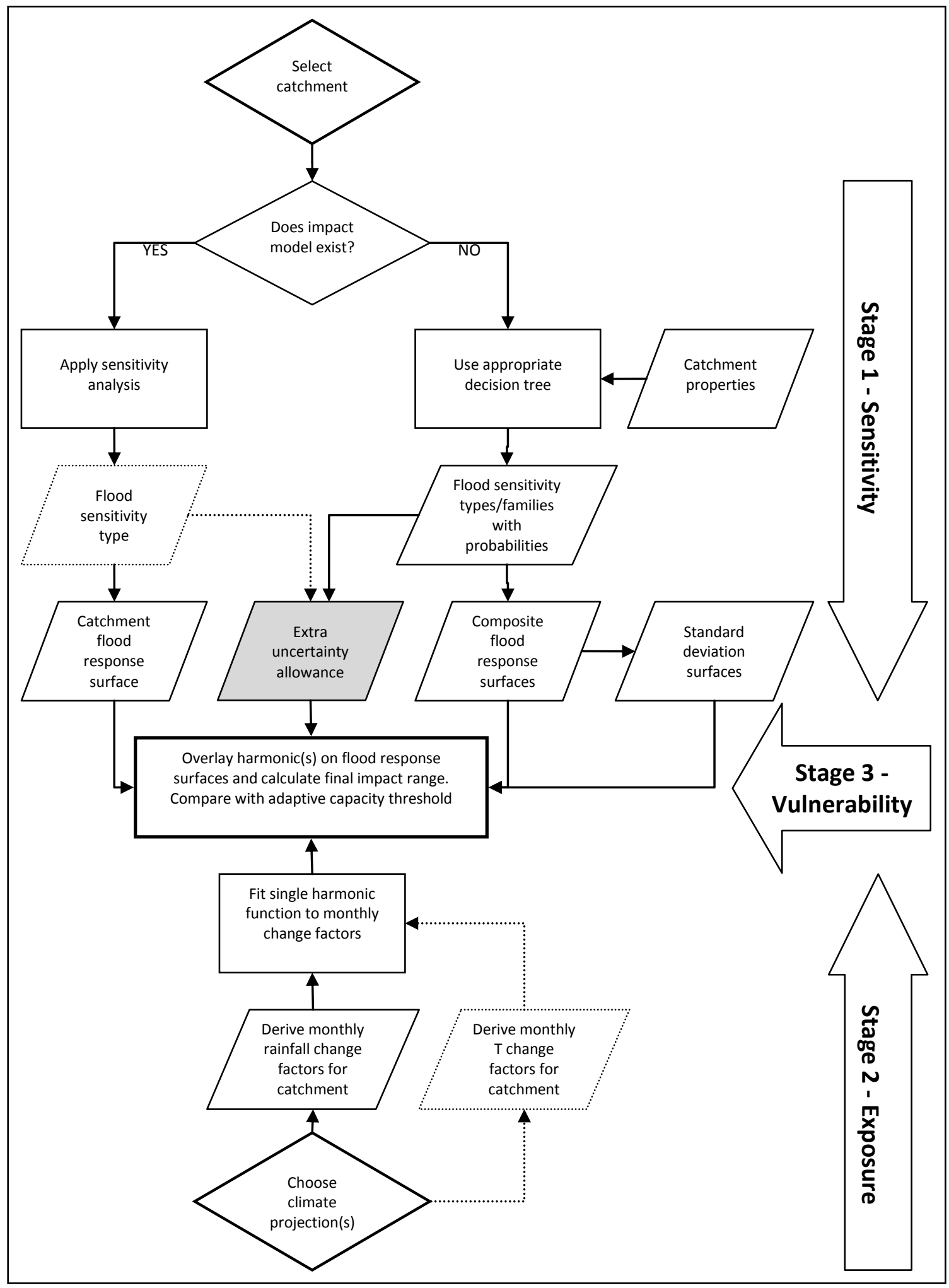




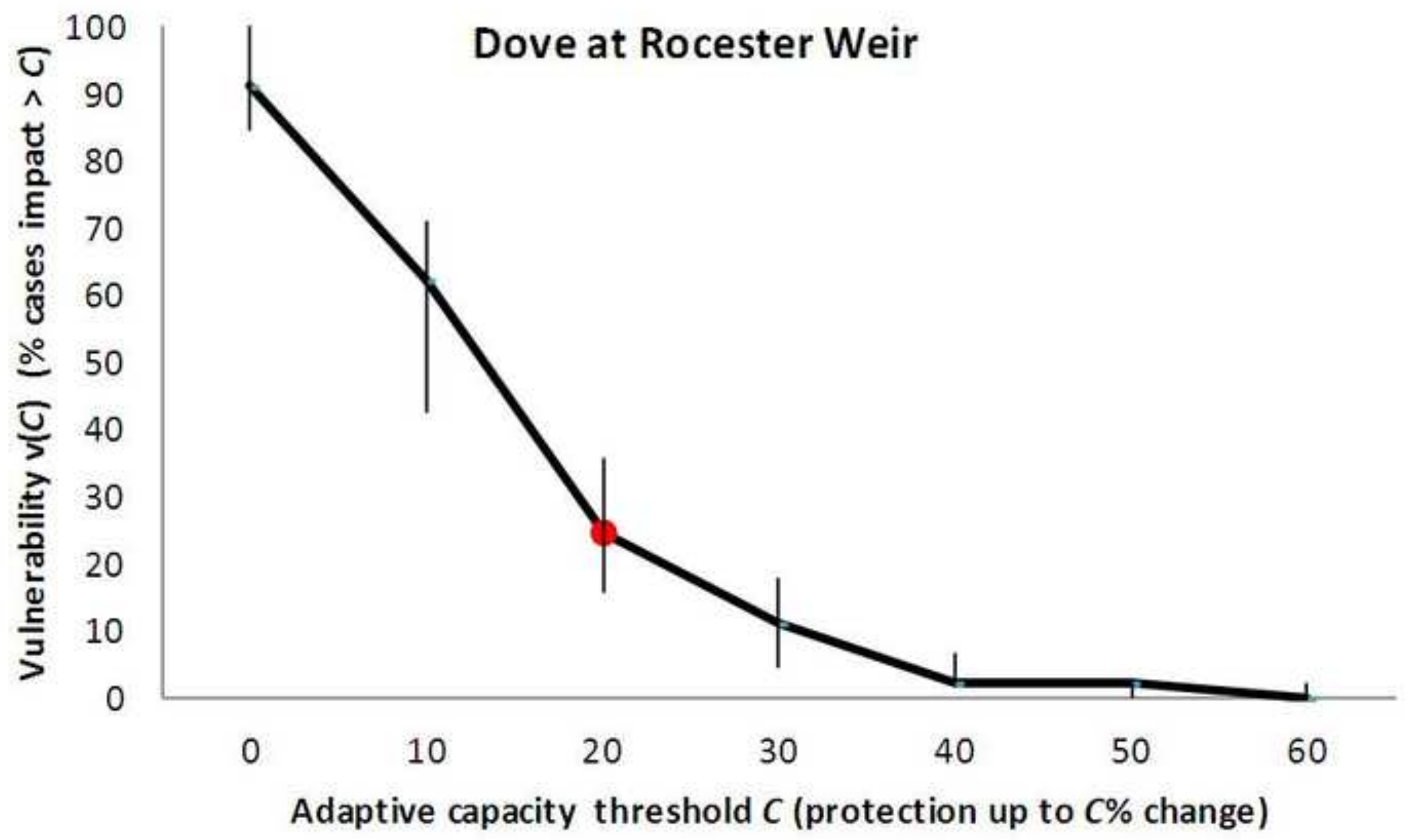




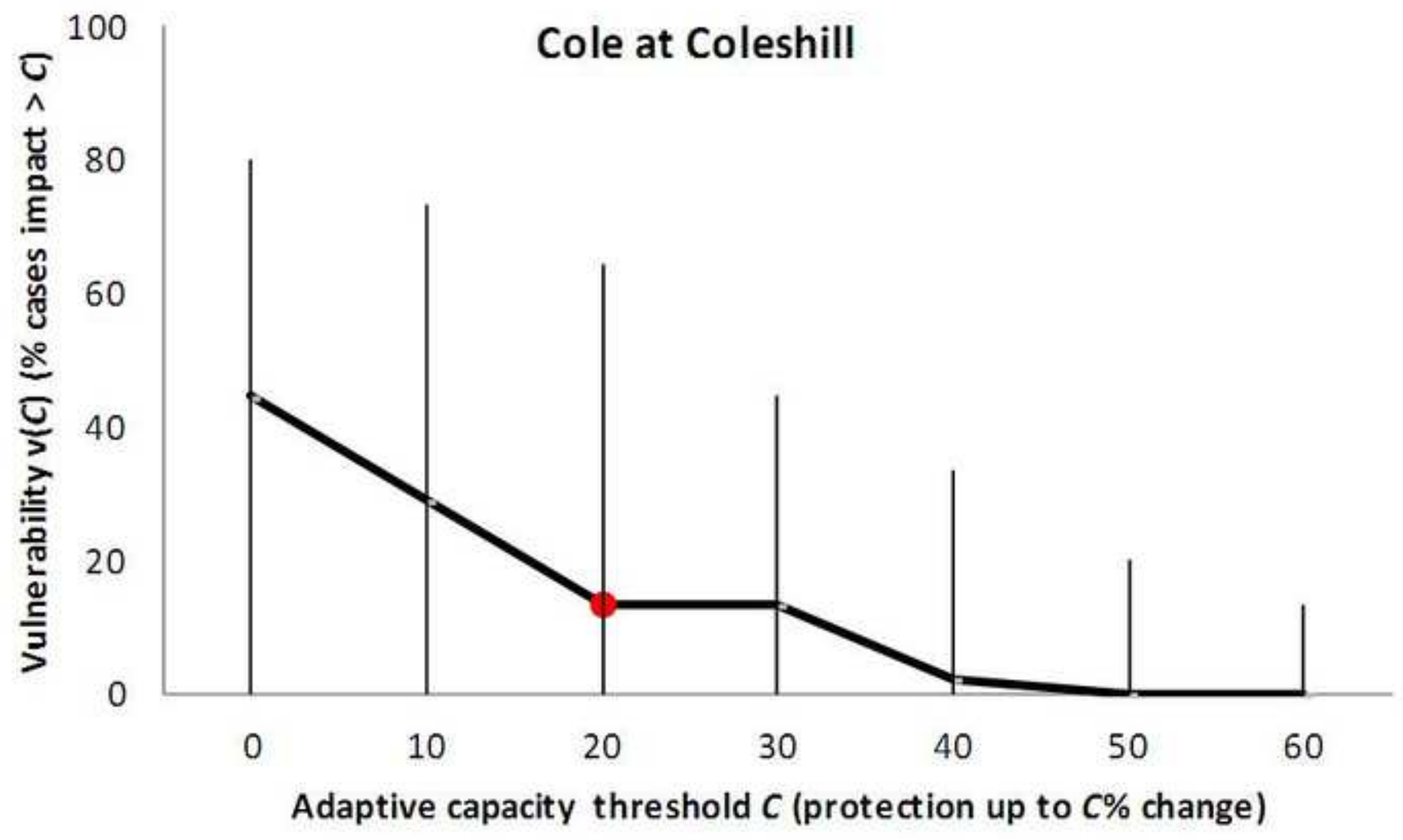


CLIMATE CHANGE AND RIVER FLOODING: PART 2 SENSITIVITY CHARACTERISATION FOR

BRITISH CATCHMENTS AND EXAMPLE VULNERABILITY ASSESSMENTS

Christel Prudhomme, Alison L. Kay, Sue Crooks, Nick Reynard

Tables:

Table 1. Schematic of the decision tree for RP20 and, for each path, the probability associated with each

flood sensitivity family and the confidence level for the highest probability family (in bold)

\begin{tabular}{|c|c|c|c|c|c|c|c|c|c|c|c|c|c|}
\hline \multicolumn{6}{|c|}{ Decision tree schematic } & \multirow{2}{*}{$\begin{array}{l}\frac{\#}{5} \\
\frac{5}{0} \\
0 \\
1\end{array}$} & \multirow{2}{*}{ 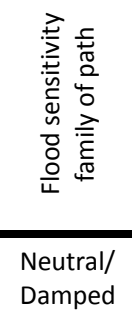 } & \multirow{2}{*}{ 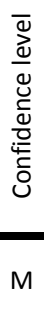 } & $\begin{array}{l}\text { Neutral/ } \\
\text { Damped }\end{array}$ & ty for flo & od sensitivi & ity family & \multirow{2}{*}{ 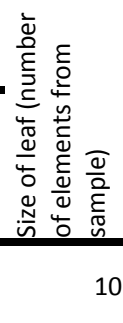 } \\
\hline \multirow{6}{*}{$\begin{array}{l}\text { SAAR } \leq \\
969.5\end{array}$} & \multirow{5}{*}{$\begin{array}{l}\mathrm{MAL} \leq \\
500.5\end{array}$} & \multicolumn{4}{|c|}{$\mathrm{MAL}<403.5$} & & & & 0.80 & 0.20 & 0.00 & 0.00 & \\
\hline & & \multirow{4}{*}{$\begin{array}{l}\text { MAL } \geq \\
403.5\end{array}$} & \multirow{3}{*}{$\begin{array}{l}\text { BHP < } \\
73.5\end{array}$} & \multicolumn{2}{|c|}{$\mathrm{BHP} \leq 4.5$} & 2 & Enhanced & $\mathrm{H}$ & 0.11 & 0.22 & 0.67 & 0.00 & 18 \\
\hline & & & & \multirow{2}{*}{$\begin{array}{l}\text { BHP > } \\
4.5\end{array}$} & $\begin{array}{l}\text { SAAR } \leq \\
858\end{array}$ & 3 & Mixed & $\mathrm{H}$ & 0.00 & 0.90 & 0.10 & 0.00 & 21 \\
\hline & & & & & $\begin{array}{l}\text { SAAR > } \\
858\end{array}$ & 4 & $\begin{array}{l}\text { Neutral/ } \\
\text { Damped }\end{array}$ & $L$ & 0.50 & 0.17 & 0.33 & 0.00 & 6 \\
\hline & & & \multicolumn{3}{|c|}{ BHP $\geq 73.5$} & 5 & Enhanced & $\mathrm{H}$ & 0.09 & 0.00 & 0.82 & 0.09 & 11 \\
\hline & \multicolumn{5}{|c|}{ MAL > 500.5} & 6 & Sensitive & $M$ & 0.00 & 0.00 & 0.27 & 0.73 & 11 \\
\hline \multirow{3}{*}{$\begin{array}{l}\text { SAAR > } \\
969.5\end{array}$} & \multirow{2}{*}{$\begin{array}{l}\text { North } \leq \\
403275\end{array}$} & \multicolumn{4}{|c|}{ Area $<781.09$} & 7 & $\begin{array}{l}\text { Neutral/ } \\
\text { Damped }\end{array}$ & $\mathrm{H}$ & 0.91 & 0.09 & 0.00 & 0.00 & 23 \\
\hline & & \multicolumn{4}{|c|}{ Area $\geq 781.09$} & 8 & Mixed & $\mathrm{L}$ & 0.00 & 0.57 & 0.43 & 0.00 & 7 \\
\hline & \multicolumn{5}{|c|}{ North > 403275} & 9 & $\begin{array}{l}\text { Neutral/ } \\
\text { Damped }\end{array}$ & $\mathrm{H}$ & 1.00 & 0.00 & 0.00 & 0.00 & 45 \\
\hline
\end{tabular}

Table 2. Description and catchment properties of two contrasting example catchments (from Marsh and

Hannaford, 2008)

\begin{tabular}{|c|c|c|c|c|c|c|c|c|}
\hline $\begin{array}{l}\text { NRFA } \\
\text { ID }\end{array}$ & River & $\begin{array}{l}\text { Gauging } \\
\text { station }\end{array}$ & Description & $\begin{array}{l}\text { Area } \\
\mathrm{km}^{2}\end{array}$ & North & $\begin{array}{l}\text { BHP } \\
\% \\
\end{array}$ & $\begin{array}{l}\text { SAAR } \\
\mathrm{mm}\end{array}$ & $\begin{array}{l}\mathrm{MAL} \\
\mathrm{mm}\end{array}$ \\
\hline 28008 & Dove & $\begin{array}{l}\text { Rocester } \\
\text { Weir }\end{array}$ & $\begin{array}{l}\text { Predominantly upland catchment with headwaters draining } \\
\text { Millstone Grit and Carboniferous Limestone while lower } \\
\text { reaches are Permian and Triassic Sandstones and Triassic } \\
\text { Limestones, with some superficial deposits within river } \\
\text { valleys. Land use is predominantly moorland and pasture }\end{array}$ & 401 & 339750 & 8 & 1020 & 445 \\
\hline 28066 & Cole & Coleshill & $\begin{array}{l}\text { Substantially urbanised catchment. Underlying geology: } \\
\text { mercia mudstone with extensive coverings of Boulder clay and } \\
\text { glacial sand and gravel }\end{array}$ & 120 & 287500 & 0 & 723 & 508 \\
\hline
\end{tabular}


Table 3. Exposure and associated impact for the Dove at Rocester Weir and the Cole at Coleshill, using a multi-model and multi-emission ensemble of projections for the 2080s. Exposure is defined by harmonic function parameters $\left(A, X_{0}, \Phi\right)$ fitted to the median of resampled monthly precipitation change factors for the most appropriate GCM grid cell for each catchment, for 17 CMIP3 GCMs and three SRES emissions scenarios (see Prudhomme et al., 2010). Impact on RP20 is given as the percentage change defined from the composite response surface (Chg) with associated uncertainty due to use of composite response surfaces to represent a range of modelled response surfaces (standard deviation SD).

\begin{tabular}{|c|c|c|c|c|c|c|c|c|c|c|c|}
\hline \multirow{3}{*}{$\begin{array}{l}\text { Emissions } \\
\text { scenario }\end{array}$} & \multirow{3}{*}{$\mathrm{GCM}$} & \multicolumn{5}{|c|}{$\begin{array}{l}\text { Dove at Rocester Weir (NRFA 28008): } \\
\text { Neutral }\end{array}$} & \multicolumn{5}{|c|}{$\begin{array}{l}\text { Cole at Coleshill (NRFA 28066): } \\
\text { Sensitive }\end{array}$} \\
\hline & & \multicolumn{3}{|c|}{ Exposure } & \multicolumn{2}{|c|}{$\begin{array}{c}\text { Impact } \\
\text { RP20 (\%) }\end{array}$} & \multicolumn{3}{|c|}{ Exposure } & \multicolumn{2}{|c|}{$\begin{array}{c}\text { Impact } \\
\text { RP20 (\%) }\end{array}$} \\
\hline & & $A$ & $X_{0}$ & $\Phi^{*}$ & Chg & SD & $A$ & $X_{0}$ & $\Phi^{*}$ & Chg & SD \\
\hline A1B & $\mathrm{BCM} 2$ & 31.8 & 3.8 & 1.9 & 32 & 3 & 23.6 & 7.5 & 1.1 & 32 & 22 \\
\hline A1B & CGMR & 8.2 & 12.1 & 10.5 & 18 & 2 & 8.2 & 12.1 & 10.5 & 13 & 18 \\
\hline A1B & CNCM3 & 34.2 & -8.4 & 1.3 & 20 & 3 & 31.2 & 3.9 & 0.8 & 20 & 18 \\
\hline A1B & CSMK3 & 1.9 & 1.0 & 10.7 & -2 & 2 & 1.9 & 1.0 & 10.7 & -25 & 12 \\
\hline A1B & ECHOG & 15.4 & 14.6 & 1.3 & 28 & 2 & 15.4 & 14.6 & 1.3 & 37 & 23 \\
\hline A1B & GFCM20 & 23.7 & -5.4 & 1.0 & 16 & 2 & 23.7 & -5.4 & 1.0 & -17 & 13 \\
\hline A1B & GFCM21 & 17.6 & -1.9 & 0.9 & 16 & 2 & 39.1 & -7.3 & 1.3 & 1 & 15 \\
\hline A1B & HADGEM & 14.5 & -6.2 & 1.3 & 6 & 2 & 14.5 & -6.2 & 1.3 & -27 & 12 \\
\hline A1B & INCM3 & 10.2 & 5.6 & 1.9 & 13 & 2 & 10.7 & 5.6 & 1.9 & -4 & 15 \\
\hline A1B & IPCM4 & 5.6 & -5.5 & 3.2 & -3 & 2 & 5.6 & -5.5 & 3.2 & -34 & 11 \\
\hline A1B & MIMR & 10.0 & 9.9 & 2.9 & 18 & 2 & 20.6 & 3.7 & 1.6 & 7 & 16 \\
\hline A1B & MPEH5 & 0.7 & 15.0 & 11.4 & 15 & 2 & 0.7 & 15.0 & 11.4 & 20 & 20 \\
\hline A1B & MRCGCM & 11.3 & 3.7 & 4.8 & 13 & 2 & 6.9 & 6.5 & 11.3 & -8 & 14 \\
\hline A1B & NCCCSM & 20.6 & -12.5 & 0.9 & 5 & 2 & 20.6 & -12.5 & 0.9 & -34 & 11 \\
\hline A1B & NCPCM & 11.7 & 1.7 & 1.5 & 7 & 2 & 11.9 & 6.3 & 2.0 & -4 & 15 \\
\hline $\mathrm{A} 2$ & $\mathrm{BCM} 2$ & 39.0 & 13.1 & 1.2 & 54 & 4 & 28.6 & 12.3 & 1.4 & 39 & 23 \\
\hline $\mathrm{A} 2$ & CGMR & 15.6 & 15.4 & 11.1 & 29 & 2 & 15.6 & 15.4 & 11.1 & 38 & 23 \\
\hline $\mathrm{A} 2$ & CNCM3 & 50.0 & -9.1 & 1.3 & 36 & 3 & 36.1 & 1.4 & 1.0 & 10 & 16 \\
\hline $\mathrm{A} 2$ & CSMK3 & 2.5 & 8.7 & 1.4 & 14 & 2 & 2.5 & 8.7 & 1.4 & 7 & 17 \\
\hline $\mathrm{A} 2$ & ECHOG & 20.8 & 14.1 & 1.1 & 12 & 2 & 20.8 & 14.1 & 1.1 & 45 & 25 \\
\hline $\mathrm{A} 2$ & GFCM20 & 30.4 & -9.6 & 1.1 & 15 & 3 & 30.4 & -9.6 & 1.1 & -25 & 12 \\
\hline $\mathrm{A} 2$ & GFCM21 & 19.1 & -2.4 & 0.78 & 16 & 2 & 41.0 & -9.1 & 1.5 & -14 & 13 \\
\hline $\mathrm{A} 2$ & GIER & 28.7 & 2.6 & 1.9 & 32 & 3 & 28.7 & 2.6 & 1.9 & 20 & 18 \\
\hline $\mathrm{A} 2$ & HADCM3 & 37.1 & -3.2 & 1.4 & 26 & 3 & 37.1 & -3.2 & 1.4 & -5 & 14 \\
\hline $\mathrm{A} 2$ & HADGEM & 16.6 & -6.0 & 0.4 & 6 & 2 & 16.6 & -6.0 & 0.4 & -27 & 12 \\
\hline $\mathrm{A} 2$ & INCM3 & 12.8 & 7.3 & 1.6 & 17 & 2 & 12.8 & 7.3 & 1.6 & 1 & 16 \\
\hline $\mathrm{A} 2$ & IPCM4 & 11.2 & -4.4 & 0.8 & 1 & 2 & 11.2 & -4.4 & 0.8 & -31 & 11 \\
\hline $\mathrm{A} 2$ & MIMR & 5.6 & 11.3 & 1.3 & 14 & 2 & 18.1 & 2.8 & 1.1 & 7 & 16 \\
\hline $\mathrm{A} 2$ & MPEH5 & 11.4 & 12.9 & 9.2 & 24 & 2 & 11.4 & 12.9 & 9.2 & 31 & 22 \\
\hline $\mathrm{A} 2$ & MRCGCM & 7.3 & 6.5 & 4.7 & 8 & 1 & 9.9 & 12.4 & 0.3 & 13 & 18 \\
\hline $\mathrm{A} 2$ & NCCCSM & 27.1 & -17.9 & 0.4 & -1 & 3 & 27.1 & -17.9 & 0.4 & -49 & 9 \\
\hline $\mathrm{A} 2$ & NCPCM & 10.0 & -0.2 & 2.8 & 7 & 2 & 9.8 & 5.8 & 1.3 & -4 & 15 \\
\hline B1 & $\mathrm{BCM} 2$ & 29.1 & 9.4 & 1.5 & 38 & 3 & 24.2 & 4.8 & 1.4 & 13 & 17 \\
\hline B1 & CNCM3 & 27.7 & -3.0 & 1.2 & 21 & 3 & 24.3 & 3.8 & 1.1 & 13 & 17 \\
\hline B1 & CSMK3 & 6.3 & 3.8 & 1.1 & 8 & 1 & 6.3 & 3.8 & 1.1 & -8 & 14 \\
\hline B1 & GFCM20 & 9.4 & 1.3 & 0.8 & 7 & 2 & 9.4 & 1.3 & 0.8 & -18 & 13 \\
\hline B1 & GFCM21 & 6.2 & -0.7 & 0.8 & 2 & 2 & 18.9 & -5.4 & 1.0 & -22 & 12 \\
\hline B1 & GIER & 12.2 & 2.7 & 1.4 & 13 & 2 & 12.2 & 2.7 & 1.4 & -4 & 15 \\
\hline B1 & HADCM3 & 24.0 & 1.9 & 1.0 & 21 & 2 & 24.0 & 1.9 & 1.0 & -3 & 15 \\
\hline B1 & INCM3 & 7.8 & 4.0 & 2.5 & 13 & 2 & 7.8 & 4.0 & 2.5 & -4 & 15 \\
\hline B1 & IPCM4 & 4.1 & 3.0 & 5.8 & 8 & 1 & 4.1 & 3.0 & 5.7 & -8 & 14 \\
\hline B1 & MIMR & 6.1 & 9.2 & 8.5 & 14 & 2 & 7.8 & 3.4 & 2.4 & -4 & 15 \\
\hline B1 & MPEH5 & 2.1 & 9.4 & 3.6 & 10 & 2 & 2.1 & 9.4 & 4.0 & 3 & 16 \\
\hline B1 & MRCGCM & 3.3 & -1.9 & 4.6 & 2 & 2 & 9.2 & 3.4 & 11.1 & -4 & 15 \\
\hline B1 & NCCCSM & 5.2 & -6.5 & 1.6 & -3 & 2 & 5.2 & -6.5 & 1.6 & -34 & 11 \\
\hline
\end{tabular}

* $\Phi$ given as month number, for information only: The impact is calculated assuming $\Phi=1$ (January) 


\section{References}

MARSH, T. J. \& HANNAFORD, J. (eds.) 2008. UK Hydrometric Register, Wallingford: Centre for Ecology and Hydrology.

PRUDHOMME, C., WILBY, L. R., CROOKS, S. M., KAY, A. L. \& REYNARD, N. S. 2010. Scenario-neutral approach to climate change impact studies: application to flood risk. Journal of Hydrology, 390, 198-209. 
CLIMATE CHANGE AND RIVER FLOODING: PART 2 SENSITIVITY CHARACTERISATION FOR BRITISH CATCHMENTS AND EXAMPLE VULNERABILITY ASSESSMENTS

Christel Prudhomme, Alison L. Kay, Sue Crooks, Nick Reynard

Tables:

Table 1. Schematic of the decision tree for RP20 and, for each path, the probability associated with each flood sensitivity family and the confidence level for the highest probability family (in bold)

Table 2. Description and catchment properties of two contrasting example catchments (from Marsh and Hannaford, 2008)

Table 3. Exposure and associated impact for the Dove at Rocester Weir and the Cole at Coleshill, using a multi-model and multi-emission ensemble of projections for the 2080s. Exposure is defined by harmonic function parameters $\left(A, X_{0}, \Phi\right)$ fitted to the median of resampled monthly precipitation change factors for the most appropriate GCM grid cell for each catchment, for 17 CMIP3 GCMs and three SRES emissions scenarios (see Prudhomme et al., 2010). Impact on RP20 is given as the percentage change defined from the composite response surface (Chg) with associated uncertainty due to use of composite response surfaces to represent a range of modelled response surfaces (standard deviation SD). 


\section{Figures:}

Figure 1. Flow chart describing the steps required for defining the vulnerability of a catchment's flood regime compared to an adaptive capacity threshold. The grey box is not fully implemented here.

Figure 2. Response surfaces showing the change in 20-year return period flood peaks for the Dove at Rochester Weir (top) and the Cole at Coleshill (bottom) obtained from local catchment modelling (left) and using the decision tree (centre; Neutral composite for the Dove, Sensitive for the Cole). Also shown is the standard deviation (SD) surface associated with each composite response surface (right). Overlaid on each composite and SD surface is a black dot indicating the location of the ECHOG A1B scenario $\left(A=15 \%, X_{0}=15 \%\right.$; see Table 3$)$.

Figure 3. Vulnerability diagram for different adaptive capacity thresholds $(C)$ for the Dove at Rochester Weir (left) and the Cole at Coleshill (right). Thick black line constructed from impact defined from exposure and composite response surface (Chg from Table 3); Uncertainty due to use of composite response surfaces to represent a range of modelled response surfaces (using Chg $\pm 2 * S D$ ) is shown as vertical bands for each C. Red symbol shows the vulnerability associated with the adaptive capacity C=20\%

\section{References}

MARSH, T. J. \& HANNAFORD, J. (eds.) 2008. UK Hydrometric Register, Wallingford: Centre for Ecology and Hydrology.

PRUDHOMME, C., WILBY, L. R., CROOKS, S. M., KAY, A. L. \& REYNARD, N. S. 2010. Scenario-neutral approach to climate change impact studies: application to flood risk. Journal of Hydrology, 390, 198-209. 

Supplementary Material
Click here to download S Click here to download Supplementary Material: Climate change and river flooding_Part2_Characterisation and Vulnerability_Supplement nent 西 西 ent 西 西


. 
Click here to download Supplementary Material: Climate change and river flooding_Part1_Sensitivity_NoEndnote_Revised_1Feb2013.doc Supplementary Material: part 1 submitted
Click here to download Supplementary Ma kere to download Supplementary Mater
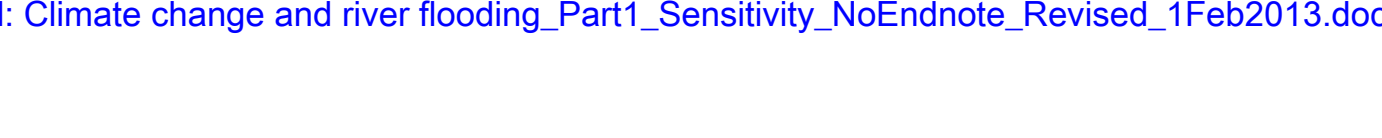
. . (1) (1) . . . . .

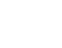

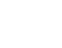


Supplementary Material: part 1 figures
Click here to download Supplementary Material: Climate change and river flooding_Part1_Sensitivity_Figures_Revised_1Feb2013.docx

Supplementary Material: part 1 figures
Click here to download Supplementary Material: Climate change and river flooding_Part1_Sensitivity_Figures_Revised_1Feb2013.docx 西 (a)

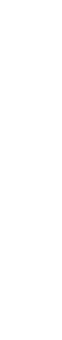
(1) (1) (1) (1) 
Click here to download Supplementary Material: Climate change and river flooding_Part1_Sensitivity_Tables_Revised_1Feb2013.docx 